\title{
Effects of spirulina and wakame consumption on intestinal cholesterol absorption and serum lipid concentrations in non-hypercholesterolemic adult men and women
}

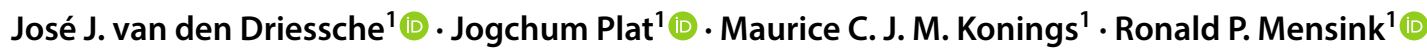

Received: 1 May 2019 / Accepted: 30 July 2019 / Published online: 6 August 2019

(c) The Author(s) 2019

\begin{abstract}
Purpose Consumption of the algae spirulina (Arthrospira platensis or maxima) and wakame (Undaria pinnatifida) has been shown to lower LDL cholesterol concentrations in animals and humans, possibly due to the inhibition of intestinal cholesterol absorption. This mechanism, however, has never been investigated in humans. Therefore, we examined in nonhypercholesterolemic men and women the effects of spirulina and wakame consumption on serum markers for intestinal cholesterol absorption.

Methods Thirty-five healthy men and women without hypercholesterolemia consumed in a random order daily $4.8 \mathrm{~g}$ spirulina, wakame or placebo for 17 days, separated by 14-day washouts. After 17 days, serum cholesterol-standardized campesterol, sitosterol and cholestanol, and lathosterol concentrations were measured as markers for intestinal cholesterol absorption and cholesterol synthesis, respectively. Concentrations of serum total cholesterol, LDL and HDL cholesterol, triacylglycerol, and plasma glucose, and blood pressure were measured as well.

Results Compared with placebo, spirulina or wakame did not affect serum cholesterol-standardized campesterol (CI -0.23 to $0.10 \mu \mathrm{mol} / \mathrm{mmol}, P=0.435$ and $\mathrm{CI}-0.14$ to $0.19 \mu \mathrm{mol} / \mathrm{mmol}, P=0.729$, respectively $)$, sitosterol $(P=0.314$ and $P=0.112)$, cholestanol $(P=0.610$ and $P=0.809)$, or lathosterol $(P=0.388$ and $P=0.102)$ concentrations. In addition, serum lipid and plasma glucose concentrations, and blood pressure were not changed.

Conclusions Daily consumption of $4.8 \mathrm{~g}$ spirulina or wakame for 17 days did not affect plasma markers for intestinal cholesterol absorption or cholesterol synthesis in non-hypercholesterolemic men and women. Serum lipid and glucose concentrations, and blood pressure were also not altered.
\end{abstract}

Keywords Spirulina $\cdot$ Wakame $\cdot$ Cholesterol $\cdot$ Intestinal cholesterol absorption $\cdot$ Humans

\section{Introduction}

Lowering serum LDL cholesterol (LDL-C) concentrations is a well-established strategy to reduce cardiovascular disease (CVD) risk [1]. This can be realized via inhibiting intestinal

Electronic supplementary material The online version of this article (https://doi.org/10.1007/s00394-019-02073-7) contains supplementary material, which is available to authorized users.

José J. van den Driessche

j.vandendriessche@maastrichtuniversity.nl

1 Department of Nutrition and Movement Sciences, NUTRIM School for Nutrition and Translational

Research in Metabolism, Maastricht University Medical Center+ (MUMC+), P.O. Box 616, 6200 MD Maastricht, The Netherlands cholesterol absorption or suppressing endogenous cholesterol synthesis [2]. In this respect, not only drugs, but also diet plays an important role. Proven examples of natural compounds or foods affecting cholesterol absorption or synthesis include plant sterols and stanols, fibers, and red yeast rice [3, 4]. However, also other foods, such as algae, may contain bioactive components that lower serum LDL-C concentrations.

Consumption of algae has gained popularity in the Western world over the past few years, due to their postulated beneficial effects on CVD risk [5, 6]. Spirulina (Arthrospira platensis or maxima), belonging to the family of cyanobacteria, is a microalga containing high amounts of proteins, vitamins and light-harvesting structures such as C-phycocyanin [7]. Animal [8, 9] and several—but not all—human trials $[10-15]$ have suggested that spirulina lowers serum 
total cholesterol (TC) and / or LDL-C concentrations. Studies in rats have now suggested that inhibition of intestinal cholesterol absorption could be the mechanism underlying the LDL-C reduction [9]. Wakame (Undaria pinnatifida) is one of the most-consumed macroalgae worldwide [16]. Constituents in wakame include the carotenoid fucoxanthin and fucoidan, a polysaccharide found in brown algae [17]. A limited number of studies have evaluated the cholesterollowering effects of wakame. Results from studies in rats on the effects of wakame [18-20] or its extract fucoxanthin [21] showed reductions in serum TC or LDL-C concentrations. On the other hand, three human studies did not show cholesterol-lowering effects of wakame [22-24], whereas a trial using fucoidan extracts from wakame did [25]. Again, inhibition of intestinal cholesterol absorption has been suggested as the underlying mechanism $[19,21]$.

Taken together, there is evidence both from human and animal studies that spirulina and wakame lower LDL-C concentrations, possibly by the inhibition of intestinal cholesterol absorption. However, this mechanism has never been examined in humans. Therefore, the aim of the present study was to evaluate in healthy, non-hypercholesterolemic men and women effects of spirulina and wakame consumption on markers for intestinal cholesterol absorption and endogenous cholesterol synthesis, and on serum lipid concentrations. Effects on glucose concentrations and blood pressure, as additional CVD risk markers [26], were studied as well.

\section{Subjects and methods}

\section{Study population}

Thirty-six apparently healthy men and women were recruited via online advertisements, posters in university and hospital buildings, and among subjects who had already participated in earlier studies within our department. Subjects were eligible for participation if they met the following criteria: aged between 18 and 70 years, BMI between 18 and $30 \mathrm{~kg} / \mathrm{m}^{2}$, non-smoking, no use of medication or food supplements known to affect lipid or glucose metabolism or blood pressure, no conditions that might interfere with study outcomes, stable body weight ( $\leq 3 \mathrm{~kg}$ weight loss or gain in the past 3 months), no participation in another biomedical trial during the past month, and no abuse of drugs or alcohol. During a screening visit, fasting blood samples were taken to exclude subjects with elevated serum TC $(\geq 8.0 \mathrm{mmol} / \mathrm{L})$, serum triacylglycerol $(\geq 4.5 \mathrm{mmol} / \mathrm{L})$ or plasma glucose $(\geq 7.0 \mathrm{mmol} / \mathrm{L}$ ) concentrations. Furthermore, weight and height were measured for the determination of BMI. All subjects signed informed consent before the screening visit. This study was approved by the medical ethical committee of Maastricht University Medical Centre+(MUMC+) and registered at clinicaltrials.gov as NCT03380611.

\section{Study design and intervention products}

The study had a randomized, placebo-controlled, doubleblind crossover design with three intervention periods of 17 days each, separated by washout periods of at least 14 days. Subjects were randomly assigned to one of the six possible treatment sequences for spirulina, wakame or placebo consumption. During the 17-day intervention periods, subjects consumed daily 12 capsules, each containing either $400 \mathrm{mg}$ spirulina (Flora Health, Burnaby, Canada), $400 \mathrm{mg}$ wakame (Swanson Health, Fargo, North Dakota, USA), or $400 \mathrm{mg}$ microcrystalline cellulose (Radboud UMC, Nijmegen, The Netherlands). Thus, in total $4.8 \mathrm{~g}$ spirulina, $4.8 \mathrm{~g}$ wakame or placebo had to be consumed daily. This dose was used since it approximates the average dosage used in former studies with spirulina and wakame [22-24, 27]. Sterol composition of the spirulina and wakame capsules was measured using gas chromatography- flame ionization detection (GC-FID) by Bonn University (Supplemental Table 1). All capsules were different in appearance and subjects were not informed about the content of the capsules. At the start of each intervention period, capsules were provided in sachets labeled with A, B or C to blind the investigator. Subjects were instructed to take four capsules directly after breakfast, lunch and dinner. Empty sachets and unused capsules had to be returned and counted as a measure of compliance. Two weeks before the start and during the study, subjects were asked to abstain from foods and products containing algae, such as sushi or seaweed salads.

Subjects visited the university at the start (day 0) and twice at the end of each intervention period (days 14 and 17). They were asked to abstain from alcohol consumption and exercise the day preceding the visits. At each visit, fasting blood samples were taken by venipuncture after an overnight fast of at least $12 \mathrm{~h}$. In addition, blood pressure and body weight were measured. At the end of each intervention period, subjects were asked to complete a validated food frequency questionnaire to assess food intake over the past 2 weeks. Energy and nutrient intakes were calculated using the Dutch food composition table (NEVO). Throughout the study, subjects were asked not to change their diets and physical activity patterns and were instructed to record daily any changes in health status and their potential alcohol consumption in a study diary.

\section{Blood sampling and analysis}

Blood was drawn into serum and sodium fluoride $(\mathrm{NaF})$ containing tubes (Becton, Dickinson and Company, Franklin Lakes, NJ, USA) at each visit. Serum separator tubes were 
allowed to clot at room temperature for 30-60 min after withdrawal. Next, the tubes were centrifuged at $1300 \times g$ for $15 \mathrm{~min}$ at $21{ }^{\circ} \mathrm{C}$ to prepare serum. NaF-containing vacutainer tubes were placed on ice immediately after withdrawal and centrifuged at $4{ }^{\circ} \mathrm{C}$ for $15 \mathrm{~min}$ at $1300 \times g$ to prepare $\mathrm{NaF}$ plasma. Serum and $\mathrm{NaF}$ plasma samples were directly frozen in liquid nitrogen and stored at $-80{ }^{\circ} \mathrm{C}$ until analysis. For all analysis, all samples from one subject were analyzed in the same analytical run.

Serum plant sterol (campesterol, sitosterol) concentrations, cholestanol, and concentrations of the cholesterol precursor lathosterol were measured in samples collected at the end of each intervention period (days 14 and 17) by GC-FID as previously described [28]. Values were standardized for total cholesterol concentrations as measured by GC-FID, and expressed as $\mu \mathrm{mol} / \mathrm{mmol}$ total cholesterol.

Serum TC concentrations (CHOD-PAP method; Roche Diagnostics System, Mannheim, Germany), HDL cholesterol (HDL-C) concentrations (precipitation method followed by CHOD-PAP method; Roche Diagnostics System), triacylglycerol concentrations corrected for free glycerol (GPO-Trinder, Sigma Diagnostics, St Louis, USA), highsensitivity C-reactive protein (hsCRP) concentrations (immunoturbidimetric assay, Horiba ABX, Montpellier, France) and plasma glucose concentrations (Horiba $\mathrm{ABX}$ ) were measured in all samples. LDL-C concentrations were calculated using the Friedewald formula [29].

\section{Blood pressure measurements}

Systolic and diastolic blood pressure was determined after a 5-minute rest in seated position during every visit (Omron M7, Omron Healthcare Co., Ltd., Kyoto, Japan). Four measurements were performed. The first measurement was discarded and the last three measurements were averaged for data analyses.

\section{Statistics}

It was estimated that a sample size of 33 subjects was needed to detect a true difference of $0.24 \mu \mathrm{mol} / \mathrm{mmol}$ in cholesterolstandardized campesterol concentrations with a power of $80 \%$ and a within-subject variability of $0.47 \mu \mathrm{mol} / \mathrm{mmol}$ [30, 31]. This effect size was chosen since earlier studies from our group showed comparable effects using plant stanol supplementation [30-32]. As the anticipated dropout rate was $10 \%, 36$ subjects were recruited.

All results are presented as means \pm SDs. Values at the end of the three periods (days 14 and 17) were averaged for all parameters. A priori, it was decided that comparisons would only be made between the spirulina and control conditions, and between the wakame and control conditions, and not between the spirulina and wakame conditions.
Differences in end-of-intervention values between spirulina or wakame and control conditions were compared using linear mixed models with subject as random factor, and treatment and period as fixed factors. Differences in endof-intervention hsCRP concentrations were compared using the non-parametric Friedman test. $P$ values $<0.05$ were considered to be statistically significant. The interaction term treatment $*$ period was used to test for carry-over effects with linear mixed models. However, this interaction term never reached statistical significance and was, therefore, removed from all models. Data were analyzed separately for men and women and baseline TC concentrations above and below $5.0 \mathrm{mmol} / \mathrm{L}$, but this did not change the conclusions. The spirulina and wakame conditions were each compared with the placebo condition using post hoc tests. To correct for multiple comparisons, $\mathrm{P}$ values $<0.025$ were then considered statistically significant. Statistical analyses were performed using SPSS 25.0 for Mac (IBM Corp., Armonk, NY, USA).

\section{Results}

\section{Subjects and compliance}

Thirty-six subjects started the intervention and one subject dropped out due to personal reasons (Fig. 1). In the end, 35 subjects (15 men and 20 women) completed the trial and were included in the statistical analyses. LDL-C data for one subject could not be calculated due to triacylglycerol concentrations above the $4.52 \mathrm{mmol} / \mathrm{L}$ threshold for reliable use of the Friedewald formula [29]. Baseline characteristics of the 35 subjects that completed the trial are shown in Table 1. Changes in weight of the subjects did not differ between the spirulina $(-0.2 \pm 0.7 \mathrm{~kg})$, wakame $(-0.1 \pm 0.6 \mathrm{~kg})$ and placebo periods $(-0.2 \pm 0.6 \mathrm{~kg} ; P=0.925$ for treatment effect). Serum hsCRP concentrations also did not differ between the three intervention periods $(P=0.450)$. Overall compliance was $99 \%$ (98.2-99.5\%) based on capsule count.

\section{Dietary intake}

Average daily intakes of energy and the macronutrients did not differ between the three intervention periods (Table 2). In addition, cholesterol and fiber intakes were also not different.

\section{Serum plant sterols, cholestanol and lathosterol concentrations}

Concentrations of cholesterol-standardized serum campesterol, sitosterol and cholestanol, markers for intestinal cholesterol absorption, did not differ between the spirulina and 
Fig. 1 Flowchart of participants throughout the study

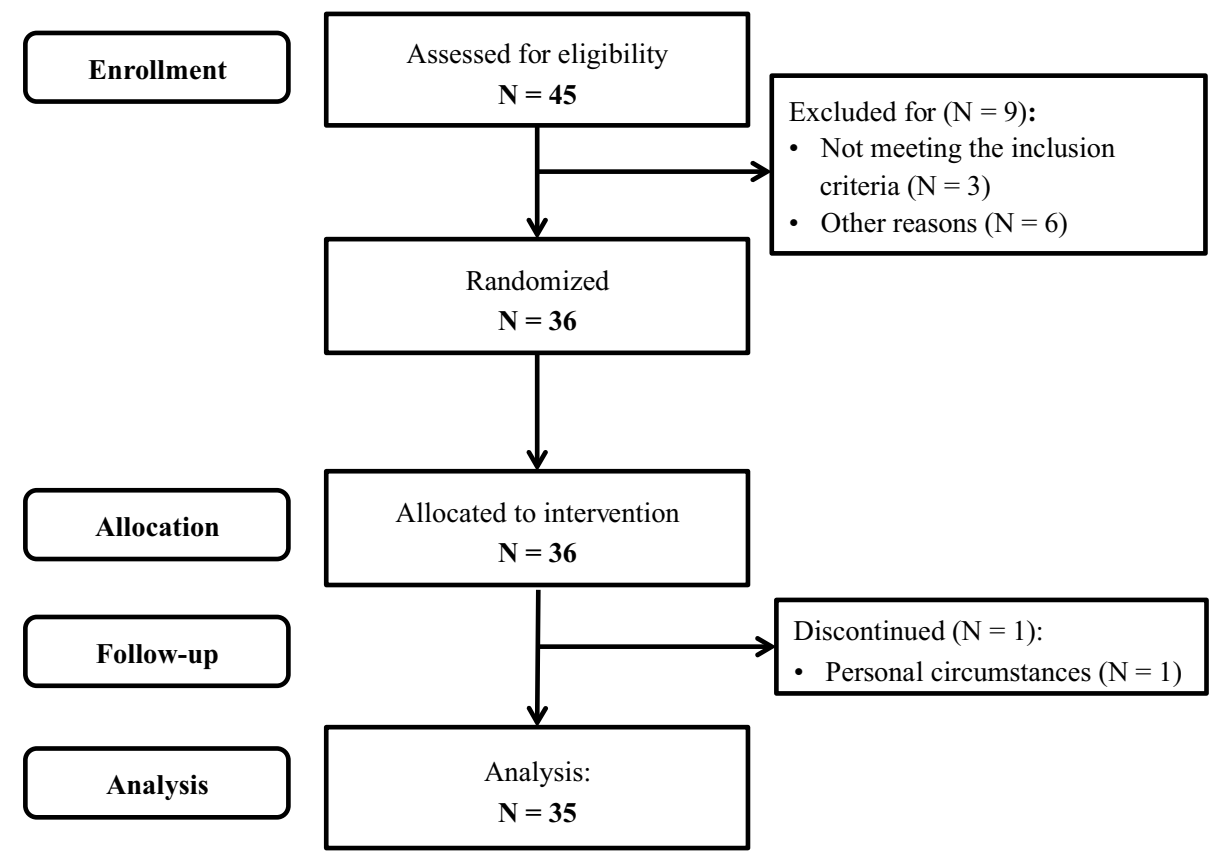

Table 1 Baseline characteristics of men and women who completed the study $(N=35)$

\begin{tabular}{ll}
\hline & Mean \pm SD \\
\hline Men/women, $n$ & $15 / 20$ \\
Age (years) & $40.2 \pm 19.6$ \\
BMI $\left(\mathrm{kg} / \mathrm{m}^{2}\right)$ & $24.7 \pm 2.7$ \\
Weight $(\mathrm{kg})$ & $71.9 \pm 12.1$ \\
Total cholesterol $(\mathrm{mmol} / \mathrm{L})$ & $4.9 \pm 1.1$ \\
HDL cholesterol $(\mathrm{mmol} / \mathrm{L})$ & $1.7 \pm 0.5$ \\
LDL cholesterol $(\mathrm{mmol} / \mathrm{L})$ & $2.7 \pm 1.0$ \\
Triacylglycerol $(\mathrm{mmol} / \mathrm{L})$ & $1.1 \pm 0.6$ \\
Glucose $(\mathrm{mmol} / \mathrm{L})$ & $5.2 \pm 1.0$ \\
\hline
\end{tabular}

Table 2 Dietary intake as assessed with food frequency questionnaires after spirulina, wakame and placebo intake

\begin{tabular}{lrrr}
\hline & Spirulina & Wakame & \multicolumn{1}{c}{ Placebo } \\
\hline Energy (MJ/day) & $9.1 \pm 2.4$ & $8.7 \pm 2.8$ & $9.2 \pm 2.9$ \\
Fat (energy \%) & $37.6 \pm 7.6$ & $37.9 \pm 7.6$ & $39.2 \pm 8.6$ \\
SFA & $12.7 \pm 3.9$ & $12.7 \pm 3.3$ & $13.2 \pm 3.4$ \\
MUFA & $14.1 \pm 3.5$ & $14.4 \pm 3.4$ & $14.9 \pm 4.0$ \\
PUFA & $7.3 \pm 2.3$ & $7.2 \pm 2.3$ & $7.6 \pm 2.9$ \\
Protein (energy \%) & $16.3 \pm 3.1$ & $16.7 \pm 3.3$ & $16.4 \pm 3.3$ \\
Carbohydrates (energy \%) & $40.5 \pm 7.1$ & $39.9 \pm 8.0$ & $39.1 \pm 8.7$ \\
Alcohol (energy \%) & $3.0 \pm 2.6$ & $3.0 \pm 2.2$ & $2.8 \pm 2.4$ \\
Fiber (g/day) & $26.3 \pm 5.5$ & $24.4 \pm 7.9$ & $24.2 \pm 5.6$ \\
Cholesterol (mg/day) & $238 \pm 113$ & $224 \pm 124$ & $256 \pm 160$ \\
\hline
\end{tabular}

SFA saturated fatty acids, MUFA monounsaturated fatty acids, $P U F A$ polyunsaturated fatty acids placebo conditions $(P=0.435, P=0.314, P=0.610$, respectively), or the wakame and placebo conditions $(P=0.729$, $P=0.112, P=0.809$, respectively; Table 3$)$. Serum cholesterol-standardized lathosterol concentrations, a marker for cholesterol synthesis, did also not differ between the spirulina or wakame and placebo conditions $(P=0.388$ and $P=0.102$, respectively).

\section{Serum lipids}

Serum lipid concentrations are shown in Table 3. No differences were found between the spirulina and placebo conditions for serum total cholesterol $(P=0.443)$, LDL-C $(P=0.677)$, HDL-C $(P=0.273)$ and triacylglycerol concentrations $(P=0.684)$. Serum total cholesterol $(P=0.749)$, LDL-C $(P=0.902)$, HDL-C $(P=0.937)$, and triacylglycerol concentrations $(P=0.302)$ did also not differ between the wakame and placebo conditions. When subjects were divided into the 50\% highest and 50\% lowest 'cholesterol absorbers' based on the median lathosterol to campesterol ratio [33], still no differences were found between the spirulina or wakame versus the control conditions within the two subgroups (Supplemental Table 2).

\section{Glucose concentrations and blood pressure}

No differences were found between the spirulina and placebo conditions for plasma glucose concentrations $(P=0.375)$, as well as between the wakame and placebo conditions $(P=0.373)$. Systolic and diastolic blood pressure did also not differ between the spirulina and placebo $(P=0.651$ and 
Table 3 Serum cholesterol-standardized concentrations of plant sterols and lathosterol, and lipid concentrations after spirulina, wakame and placebo intake $(N=35)$

\begin{tabular}{lllllr}
\hline & Spirulina & Wakame & Placebo & \multicolumn{2}{l}{ Estimated difference (versus placebo $)^{\mathrm{a}}$} \\
\cline { 3 - 6 } & & & & Spirulina & Wakame \\
\hline Campesterol $(\mu \mathrm{mol} / \mathrm{mmol})$ & $2.60 \pm 1.11$ & $2.69 \pm 1.11$ & $2.66 \pm 0.99$ & $-0.07(-0.23$ to 0.10$)$ & $0.03(-0.14$ to 0.19$)$ \\
Sitosterol $(\mu \mathrm{mol} / \mathrm{mmol})$ & $2.25 \pm 0.76$ & $2.42 \pm 0.75$ & $2.32 \pm 0.67$ & $-0.07(-0.19$ to 0.06$)$ & $0.10(-0.03$ to 0.23$)$ \\
Cholestanol $(\mu \mathrm{mol} / \mathrm{mmol})$ & $1.51 \pm 0.33$ & $1.52 \pm 0.31$ & $1.52 \pm 0.33$ & $-0.01(-0.06$ to 0.03$)$ & $-0.01(-0.05$ to 0.04$)$ \\
Lathosterol $(\mu \mathrm{mol} / \mathrm{mmol})$ & $1.58 \pm 0.52$ & $1.62 \pm 0.50$ & $1.54 \pm 0.50$ & $0.04(-0.05$ to 0.13$)$ & $0.08(-0.02$ to 0.17$)$ \\
Total cholesterol $(\mathrm{mmol} / \mathrm{L})$ & $4.75 \pm 1.00$ & $4.84 \pm 1.02$ & $4.81 \pm 1.09$ & $-0.06(-0.22$ to 0.10$)$ & $0.03(-0.13$ to 0.18$)$ \\
LDL cholesterol $(\mathrm{mmol} / \mathrm{L}) \mathrm{b}$ & $2.75 \pm 0.97$ & $2.78 \pm 1.04$ & $2.77 \pm 1.07$ & $-0.03(-0.15$ to 0.10$)$ & $0.01(-0.12$ to 0.13$)$ \\
HDL cholesterol $(\mathrm{mmol} / \mathrm{L})$ & $1.52 \pm 0.43$ & $1.56 \pm 0.42$ & $1.56 \pm 0.49$ & $-0.04(-0.11$ to 0.03$)$ & $0.00(-0.07$ to 0.07$)$ \\
Triacylglycerol $(\mathrm{mmol} / \mathrm{L})$ & $1.09 \pm 0.63$ & $1.12 \pm 0.80$ & $1.06 \pm 0.61$ & $0.02(-0.09$ to 0.14$)$ & $0.06(-0.06$ to 0.18$)$ \\
\hline
\end{tabular}

${ }^{\mathrm{a}}$ Estimated difference and $95 \%$ confidence interval (CI), based on estimated marginal means obtained with linear mixed models

${ }^{\mathrm{b}} N=34$ for LDL cholesterol concentrations

$P=0.550$, respectively; Table 4$)$, or the wakame and placebo conditions ( $P=0.620$ and $P=0.677$, respectively).

\section{Discussion}

In this placebo-controlled double-blind intervention study, daily consumption of $4.8 \mathrm{~g}$ spirulina or $4.8 \mathrm{~g}$ wakame for 17 days did not affect markers for intestinal cholesterol absorption and endogenous cholesterol synthesis in nonhypercholesterolemic healthy men and women. In agreement, serum lipid concentrations were also not affected. Also, no effects on plasma glucose concentrations and blood pressure were observed.

Animal studies have suggested that spirulina and wakame consumption inhibits intestinal cholesterol absorption. In male Wistar rats, a spirulina concentrate increased fecal steroid content with a concomitant decrease in LDL-C concentrations [9]. In two in vitro experiments, a spirulina concentrate decreased micellar solubility of cholesterol and suppressed cholesterol absorption in Caco-2 cells. Similarly, supplementation with wakame or a wakame extract increased fecal cholesterol excretion in male Wistar rats [19] and C57BL/6J mice on a high-fat diet [21], again suggesting the inhibition of intestinal cholesterol absorption. However, since serum cholesterol-standardized campesterol, sitosterol and cholestanol concentrations were not changed, our results do not suggest that these two algae did have an effect on intestinal cholesterol absorption in humans. In addition, cholesterol-standardized lathosterol concentrations, a marker reflecting endogenous cholesterol synthesis, were not altered. The use of serum non-cholesterol sterol and stanol concentrations as markers for intestinal cholesterol absorption and endogenous cholesterol synthesis has been well validated [34]. Yet, when the intake of these sterols changes, plasma levels do not reflect cholesterol absorption anymore. However, levels of sterols in the algae were very low (Supplemental Table 1) and, therefore, did not affect the validity of plasma plant sterols as markers for intestinal cholesterol absorption. In addition, cholestanol was not present in the algae and the observation that serum cholestanol concentrations were not affected confirmed the lack of an effect on intestinal cholesterol absorption.

As expected by the lack of effects on intestinal cholesterol absorption and endogenous cholesterol synthesis, serum TC or LDL-C concentrations were also unchanged. This contrasts findings from a recent meta-analysis, including 10 RCTs with 12 treatment arms and more than 700 subjects, evaluating the effects of spirulina consumption on serum lipid concentrations [27]. Decreases of $-1.00 \mathrm{mmol} / \mathrm{L}$ and $-0.91 \mathrm{mmol} / \mathrm{L}$ were reported for TC and LDL-C respectively. These effects are large for a dietary intervention and

Table 4 Plasma glucose concentrations, and systolic and diastolic blood pressures after spirulina, wakame and placebo consumption $(N=35)$

\begin{tabular}{|c|c|c|c|c|c|}
\hline & \multirow[t]{2}{*}{ Spirulina } & \multirow[t]{2}{*}{ Wakame } & \multirow[t]{2}{*}{ Placebo } & \multicolumn{2}{|c|}{ Estimated difference (versus placebo) ${ }^{a}$} \\
\hline & & & & Spirulina & Wakame \\
\hline Glucose (mmol/L) & $5.27 \pm 0.37$ & $5.27 \pm 0.39$ & $5.23 \pm 0.37$ & $0.04(-0.04$ to 0.11$)$ & $0.04(-0.04$ to 0.11$)$ \\
\hline Systolic blood pressure (mmHg) & $113.9 \pm 13.7$ & $114.1 \pm 14.3$ & $114.4 \pm 14.5$ & $-0.5(-2.8$ to 1.8$)$ & $-0.6(-2.9$ to 1.7$)$ \\
\hline Diastolic blood pressure (mmHg) & $75.4 \pm 9.4$ & $75.3 \pm 9.3$ & $74.9 \pm 9.5$ & $0.5(-1.1$ to 2.1$)$ & $0.3(-1.3$ to 1.9$)$ \\
\hline
\end{tabular}

${ }^{a}$ Estimated difference and $95 \%$ confidence interval (CI), based on estimated marginal means obtained with linear mixed models 
are in the range of those achieved with drugs [35]. Although the present study was not primarily powered on changes in LDL-C, post hoc calculations showed that the statistical power of our study was close to $100 \%$ to pick up such an effect. In the same meta-analysis, a decrease in triacylglycerol concentrations was found, whereas those of HDL-C were not significantly changed. However, 5 of the 10 RCTs measuring serum lipid concentrations were not blinded, since the control groups received no placebo capsules or tablets $[10,12-14,36]$. In fact, subgroup analysis revealed that TC, LDL-C, TAG concentrations decreased and those of HDL-C increased in the trials with a no-intervention control group. When a placebo group was included, only TC concentrations decreased. Differences in dose, duration of the intervention and study populations are factors to explore in trying to explain discrepancies in results.

Intake of spirulina differed largely between the 10 trials included in the meta-analysis ranging from 1 to $19 \mathrm{~g}$ daily, with a median intake of $2 \mathrm{~g}$. Subgroup analysis suggested that lipid-lowering effects were found with consumption of $2 \mathrm{~g}$ or more, whereas no significant effects were found with intakes less than $2 \mathrm{~g}$ a day. As our daily dose of $4.8 \mathrm{~g}$ is clearly above this median intake of $2 \mathrm{~g}$, it is unlikely that differences in spirulina dosage could explain the lack of effects.

The duration of our intervention was shorter compared to earlier trials. The median intervention duration in the metaanalyses of Huang and colleagues was 12 weeks. Subgroup analysis revealed that significant changes in lipid concentrations were only found in the 7 RCTs lasting 12 weeks or longer, but only three of them used placebos instead of a no-intervention control group. It is not likely that our shorter study duration can explain the lack of effect on LDL-C, as LDL-C concentrations reach a new steady state within 2 weeks when intestinal cholesterol absorption is inhibited by dietary components or drugs $[37,38]$.

Our study population also varied from those of other studies. Spirulina lowered TC, LDL-C and TAG, but not HDL-C concentrations in type II diabetics [11, 39] and children with the nephrotic syndrome [14]. On the other hand, two other studies in type II diabetics only reported TAG-lowering effects and no effects on TC, LDL-C and HDL-C concentrations $[10,40]$. Lipid concentrations were all improved in ischemic heart disease patients with hypercholesterolemia, whereas no effects on any of the lipid parameters were seen in obese subjects [15]. In HIV patients [12] and hypertensive subjects [41], TC and LDL-C concentrations decreased and those of HDL-C increased. In elderly, only TC concentrations were decreased [42]. Overall, heterogeneity between studies was large and there was no evidence that some populations were more responsive than others. It is, therefore, not likely that the effects of spirulina consumption are only evident in subjects with increased baseline total cholesterol concentrations and not in our healthy, non-hypercholesterolemic population. Also, studies with plant sterols and stanols have demonstrated LDL-C lowering effects via inhibition of intestinal cholesterol absorption in non-hypercholesterolemic subjects [32, 37]. In conclusion, there is no clear reason why our results do not support the results of the meta-analysis of Huang et al. [27]. Possibly, lack of blinding of some of the earlier studies may have biased outcomes.

Results of human trials investigating the effect of wakame consumption on TC or LDL-C concentrations are more in line with our results in non-hypercholesterolemic subjects. No effects were found in hypertensive subjects [22], subjects with the metabolic syndrome [23], and HIV patients [24]. In former trials, daily intakes ranged between 4 and $6 \mathrm{~g}$, which is comparable to the intake used in our study. In one study, $500 \mathrm{mg}$ of fucoidan extracted from brown seaweed lowered LDL-C concentrations in overweight and obese subjects [25]. However, this amount of fucoidan is present in 13-46 $\mathrm{g}$ of wakame [43], which is much higher than the amount of $4.8 \mathrm{~g}$ provided in our and the other studies. Whether the wakame extract fucoidan truly lowers LDL-C warrants further study.

Glucose concentrations and blood pressure were assessed as additional markers for CVD risk, but were not changed by spirulina or wakame consumption. A meta-analysis including eight RCTs suggested glucose-lowering effects of spirulina consumption [27], which is in contrast with our results. No subgroup analyses were performed. Of the 8 studies included, 4 were certainly not blinded. Decreases in fasting glucose concentrations were observed in studies with type II diabetics [11, 36, 39], HIV patients [44], and hypertensive subjects [41]. However, in two other trials with type II diabetics $[10,40]$ and a trial with children with the nephrotic syndrome [14], glucose concentrations were not affected. None of the trials with wakame reported effects on glucose concentrations [23, 24]. Diastolic blood pressure was also significantly lowered after spirulina consumption in the recent meta-analysis [34], whereas systolic blood pressure was not affected. Three studies were included in the analysis, of which two were blinded. However, in only one individual trial with hypertensive subjects, spirulina consumption significantly affected diastolic blood pressure [45]. Wakame consumption did affect systolic and diastolic blood pressure in hypertensive subjects [22] and systolic blood pressure in subjects with the metabolic syndrome [23]. In the latter trial, effects were only present in a hypertensive subgroup. Thus, it may be that algae consumption only lowers blood pressure in subjects with increased baseline blood pressure levels. Although this needs to be explored further, it might explain the lack of an effect on blood pressure in our trial with non-hypertensive subjects.

To conclude, our study indicates that consuming $4.8 \mathrm{~g} /$ day spirulina or wakame for 17 days does not inhibit intestinal 
cholesterol absorption in non-hypercholesterolemic men and women, nor does it affect lipid profiles. In addition, blood pressure and glucose concentrations were not affected by spirulina or wakame consumption.

Acknowledgements The authors would like to thank Maud Beckers and Lynn Vrenken for technical and dietary support throughout the study. We thank Dieter Lutjohann and Kenneth Vanbrabant from Bonn University for analyzing the sterol composition from spirulina and wakame.

\section{Compliance with ethical standards}

Conflict of interest The authors declare that they have no conflict of interest.

Ethical approval The current study was approved by the medical ethical committee of Maastricht University Medical Centre+ (MUMC+) and has, therefore, been performed in accordance with the ethical standards laid down in the 1964 Declaration of Helsinki and its later amendments. All subjects signed informed consent prior to their inclusion in the study.

Open Access This article is distributed under the terms of the Creative Commons Attribution 4.0 International License (http://creativeco mmons.org/licenses/by/4.0/), which permits unrestricted use, distribution, and reproduction in any medium, provided you give appropriate credit to the original author(s) and the source, provide a link to the Creative Commons license, and indicate if changes were made.

\section{References}

1. Cholesterol Treatment Trialists' (CTT) Collaboration (2012) The effects of lowering LDL cholesterol with statin therapy in people at low risk of vascular disease: meta-analysis of individual data from 27 randomised trials. Lancet 380(9841):581-590.https://doi. org/10.1016/s0140-6736(12)60367-5

2. Cohen DE (2008) Balancing cholesterol synthesis and absorption in the gastrointestinal tract. J Clin Lipidol 2(2):S1-S3. https://doi. org/10.1016/j.jacl.2008.01.004

3. Brown L, Rosner B, Willett WW, Sacks FM (1999) Cholesterollowering effects of dietary fiber: a meta-analysis. Am J Clin Nutr 69(1):30-42. https://doi.org/10.1093/ajen/69.1.30

4. Feuerstein JS, Bjerke WS (2012) Powdered red yeast rice and plant stanols and sterols to lower cholesterol. J Diet Suppl 9(2):110-115

5. van den Driessche JJ, Plat J, Mensink RP (2018) Effects of superfoods on risk factors of metabolic syndrome: a systematic review of human intervention trials. Food Funct 9(4):1944-1966. https ://doi.org/10.1039/c7fo01792h

6. Wells ML, Potin P, Craigie JS, Raven JA, Merchant SS, Helliwell KE, Smith AG, Camire ME, Brawley SH (2017) Algae as nutritional and functional food sources: revisiting our understanding. J Appl Phycol 29(2):949-982. https://doi.org/10.1007/s1081 1-016-0974-5

7. Buono S, Langellotti AL, Martello A, Rinna F, Fogliano V (2014) Functional ingredients from microalgae. Food Funct 5(8):16691685. https://doi.org/10.1039/c4fo00125g
8. Iwata K, Inayama T, Kato T (1990) Effects of Spirulina platensis on plasma lipoprotein lipase activity in fructose-induced hyperlipidemic rats. J Nutr Sci Vitaminol 36(2):165-171

9. Nagaoka S, Shimizu K, Kaneko H, Shibayama F, Morikawa K, Kanamaru Y, Otsuka A, Hirahashi T, Kato T (2005) A novel protein C-phycocyanin plays a crucial role in the hypocholesterolemic action of Spirulina platensis concentrate in rats. J Nutr 135(10):2425-2430

10. Lee EH, Park JE, Choi YJ, Huh KB, Kim WY (2008) A randomized study to establish the effects of spirulina in type 2 diabetes mellitus patients. Nutr Res Pract 2(4):295-300. https://doi. org/10.4162/nrp.2008.2.4.295

11. Mani UV, Desai S, Iyer U (2000) Studies on the long-term effect of spirulina supplementation on serum lipid profile and glycated proteins in NIDDM patients. J Nutraceutic Functi Med Foods 2(3):25-32. https://doi.org/10.1300/J133v02n03_03

12. Ngo-Matip ME, Pieme CA, Azabji-Kenfack M, Biapa PC, Germaine N, Heike E, Moukette BM, Emmanuel K, Philippe S, Mbofung CM, Ngogang JY (2014) Effects of Spirulina platensis supplementation on lipid profile in HIV-infected antiretroviral naive patients in Yaounde-Cameroon: a randomized trial study. Lipids Health Dis 13:191. https://doi.org/10.1186/1476-511x-13-191

13. Ramamoorthy A, Premakumari S (1996) Effect of supplementation of spirulina on hypercholesterolemic patients. J Food Sci Technol 33(2):124-128

14. Samuels R, Mani UV, Iyer UM, Nayak US (2002) Hypocholesterolemic effect of spirulina in patients with hyperlipidemic nephrotic syndrome. J Med Food 5(2):91-96. https://doi. org/10.1089/109662002760178177

15. Zeinalian R, Farhangi MA, Shariat A, Saghafi-Asl M (2017) The effects of Spirulina Platensis on anthropometric indices, appetite, lipid profile and serum vascular endothelial growth factor (VEGF) in obese individuals: a randomized double blinded placebo controlled trial. BMC Complement Altern Med 17(1):225. https://doi. org/10.1186/s12906-017-1670-y

16. Zava TT, Zava DT (2011) Assessment of Japanese iodine intake based on seaweed consumption in Japan: a literature-based analysis. Thyroid Res 4:14. https://doi.org/10.1186/1756-6614-4-14

17. Zhang H, Pang Z, Han C (2014) Undaria pinnatifida (Wakame): a seaweed with pharmacological properties. Sci Int 2(2):32-36

18. Grasa-López A, Miliar-García Á, Quevedo-Corona L, PaniaguaCastro N, Escalona-Cardoso G, Reyes-Maldonado E, JaramilloFlores M-E (2016) Undaria pinnatifida and fucoxanthin ameliorate lipogenesis and markers of both inflammation and cardiovascular dysfunction in an animal model of diet-induced obesity. Mar Drugs 14(8):148. https://doi.org/10.3390/md14080148

19. Iritani N, Nogi J (1972) Effect of spinach and wakame on cholesterol turnover in the rat. Atherosclerosis 15(1):87-92

20. Yoshinaga K, Nakai Y, Izumi H, Nagaosa K, Ishijima T, Nakano T, Abe K (2018) Oral administration of edible seaweed Undaria pinnatifida (wakame) modifies glucose and lipid metabolism in rats: a DNA microarray analysis. Mol Nutr Food Res 62(12):e1700828. https://doi.org/10.1002/mnfr.201700828

21. Jeon SM, Kim HJ, Woo MN, Lee MK, Shin YC, Park YB, Choi MS (2010) Fucoxanthin-rich seaweed extract suppresses body weight gain and improves lipid metabolism in high-fatfed C57BL/6J mice. Biotechnol J 5(9):961-969. https://doi. org/10.1002/biot.201000215

22. Hata Y, Nakajima K, Uchida J-i, Hidaka H, Nakano T (2001) Clinical effects of brown seaweed, Undariapinnatifida (wakame), on blood pressure in hypertensive subjects. J Clin Biochem Nutr 30:43-53. https://doi.org/10.3164/jcbn.30.43

23. Teas J, Baldeon ME, Chiriboga DE, Davis JR, Sarries AJ, Braverman LE (2009) Could dietary seaweed reverse the metabolic syndrome? Asia Pac J Clin Nutr 18(2):145-154 
24. Teas J, Irhimeh MR (2012) Dietary algae and HIV/AIDS: proof of concept clinical data. J Appl Phycol 24(3):575-582. https://doi. org/10.1007/s10811-011-9766-0

25. Hernandez-Corona DM, Martinez-Abundis E, Gonzalez-Ortiz M (2014) Effect of fucoidan administration on insulin secretion and insulin resistance in overweight or obese adults. J Med Foods 17(7):830-832. https://doi.org/10.1089/jmf.2013.0053

26. Alberti KG, Eckel RH, Grundy SM, Zimmet PZ, Cleeman JI, Donato KA, Fruchart JC, James WP, Loria CM, Smith SC Jr (2009) Harmonizing the metabolic syndrome: a joint interim statement of the International Diabetes Federation Task Force on Epidemiology and Prevention; National Heart, Lung, and Blood Institute; American Heart Association; World Heart Federation; International Atherosclerosis Society; and International Association for the Study of Obesity. Circulation 120(16):1640-1645. https://doi.org/10.1161/circulationaha.109.192644

27. Huang H, Liao D, Pu R, Cui Y (2018) Quantifying the effects of spirulina supplementation on plasma lipid and glucose concentrations, body weight, and blood pressure. Diabetes Metab Syndr Obes Targets Ther 11:729-742. https://doi.org/10.2147/dmso. s185672

28. Teunissen CE, Mulder M, de Vente J, von Bergmann K, De Bruijn C, Steinbusch HW, Lutjohann D (2001) Concentrations of different sterols in the striatum and serum of 3-nitropropionic acidtreated Wistar and Lewis rats. Neurochem Res 26(11):1237-1244

29. Friedewald WT, Levy RI, Fredrickson DS (1972) Estimation of the concentration of low-density lipoprotein cholesterol in plasma, without use of the preparative ultracentrifuge. Clin Chem 18(6):499-502

30. Brull F, De Smet E, Mensink RP, Vreugdenhil A, Kerksiek A, Lutjohann D, Wesseling G, Plat J (2016) Dietary plant stanol ester consumption improves immune function in asthma patients: results of a randomized, double-blind clinical trial. Am J Clin Nutr 103(2):444-453. https://doi.org/10.3945/ajen.115.117531

31. Mensink RP, de Jong A, Lutjohann D, Haenen GR, Plat J (2010) Plant stanols dose-dependently decrease LDL-cholesterol concentrations, but not cholesterol-standardized fat-soluble antioxidant concentrations, at intakes up to $9 \mathrm{~g} / \mathrm{d}$. Am J Clin Nutr 92(1):2433. https://doi.org/10.3945/ajen.2009.29143

32. Baumgartner S, Mensink RP, Husche C, Lutjohann D, Plat J (2013) Effects of plant sterol- or stanol-enriched margarine on fasting plasma oxyphytosterol concentrations in healthy subjects. Atherosclerosis 227(2):414-419. https://doi.org/10.1016/j.ather osclerosis.2013.01.012

33. Thuluva SC, Igel M, Giesa U, Lutjohann D, Sudhop T, von Bergmann K (2005) Ratio of lathosterol to campesterol in serum predicts the cholesterol-lowering effect of sitostanol-supplemented margarine. Int J Clin Pharmacol Ther 43(7):305-310

34. Miettinen TA, Tilvis RS, Kesaniemi YA (1990) Serum plant sterols and cholesterol precursors reflect cholesterol absorption and synthesis in volunteers of a randomly selected male population. Am Journal Epidemiol 131(1):20-31
35. Ohta A, Kato H, Ishii S, Nagai Y, Tanaka Y (2017) Effect of ezetimibe monotherapy on low-density lipoprotein cholesterol and on markers of cholesterol synthesis and absorption in Japanese patients with hypercholesterolemia. J Clin Med Res 9(6):476-481. https://doi.org/10.14740/jocmr2782w

36. Anitha L, Chandralekha K (2010) Effect of supplementation of Spirulina on blood glucose, glycosylated hemoglobin and lipid profile of male non-insulin dependent diabetics. Asian J Exp Biol Sci 1(1):36-46

37. Mensink RP, Ebbing S, Lindhout M, Plat J, van Heugten MM (2002) Effects of plant stanol esters supplied in low-fat yoghurt on serum lipids and lipoproteins, non-cholesterol sterols and fat soluble antioxidant concentrations. Atherosclerosis 160(1):205-213

38. Knopp RH, Gitter H, Truitt T, Bays H, Manion CV, Lipka LJ, LeBeaut AP, Suresh R, Yang B, Veltri EP (2003) Effects of ezetimibe, a new cholesterol absorption inhibitor, on plasma lipids in patients with primary hypercholesterolemia. Eur Heart J 24(8):729-741

39. Kamalpreet K, Rajbir S, Kiran G (2008) Effect of supplementation of Spirulina on blood glucose and lipid profile of the noninsulin dependent diabetic male subjects. J Dairy Foods Home Sci 27(3and4):202-208

40. Parikh P, Mani U, Iyer U (2001) Role of spirulina in the control of glycemia and lipidemia in type 2 diabetes mellitus. J Med Food 4(4):193-199. https://doi.org/10.1089/10966200152744463

41. Szulinska M, Gibas-Dorna M, Miller-Kasprzak E, Suliburska J, Miczke A, Walczak-Galezewska M, Stelmach-Mardas M, Walkowiak J, Bogdanski P (2017) Spirulina maxima improves insulin sensitivity, lipid profile, and total antioxidant status in obese patients with well-treated hypertension: a randomized double-blind placebo-controlled study. Eur Rev Med Pharmacol Sci 21(10):2473-2481

42. Park HJ, Lee YJ, Ryu HK, Kim MH, Chung HW, Kim WY (2008) A randomized double-blind, placebo-controlled study to establish the effects of spirulina in elderly Koreans. Ann Nutr Metab 52(4):322-328. https://doi.org/10.1159/000151486

43. Lee YK, Lim D-J, Lee Y-H, Park Y-I (2006) Variation in fucoidan contents and monosaccharide compositions of Korean Undariapinnatifida (Harvey) suringar (Phaeophyta). Algae 21(1):157-160. https://doi.org/10.4490/algae.2006.21.1.157

44. Ngo-Matip M-E, Pieme CA, Azabji-Kenfack M, Moukette BM, Korosky E, Stefanini P, Ngogang JY, Mbofung CM (2015) Impact of daily supplementation of Spirulina platensis on the immune system of naïve HIV-1 patients in Cameroon: a 12-months single blind, randomized, multicenter trial. Nutr J 14:70-70. https://doi. org/10.1186/s12937-015-0058-4

45. Miczke A, Szulinska M, Hansdorfer-Korzon R, KregielskaNarozna M, Suliburska J, Walkowiak J, Bogdanski P (2016) Effects of spirulina consumption on body weight, blood pressure, and endothelial function in overweight hypertensive Caucasians: a double-blind, placebo-controlled, randomized trial. Eur Rev Med Pharmacol Sci 20(1):150-156 